\title{
State of the art review of the application of strain energy density in design against fatigue of welded joints
}

\author{
Kaynaklı birleştirmelerin yorulmaya karşı tasarımında birim şekil \\ değiştirme enerji yoğunluğu uygulamalarının güncel incelemesi
}

\author{
Özler KARAKAŞ' $1^{*}$ iD , Nail TÜZÜN ${ }^{2}$ iD \\ 1,2Deparment of Mechanical Engineering, Engineering Faculty, Pamukkale University, Denizli, Turkey. \\ okarakas@pau.edu.tr, nailtuzun@gmail.com
}

\begin{abstract}
Design of mechanical components against fatigue is vitally important to prevent sudden and unexpected fatigue damage. Due to the complex nature of welded joints because of the changes in material properties due to heat and the geometry of weld beads, designing against fatigue becomes an even more challenging task. Over the years, several methods that can accurately and effectively determine fatigue related parameters were developed. In this paper, a state of the art literature review of studies based on strain energy density (SED) approaches and their use in fatigue evaluations are presented. While a theoretical background is provided, the main focus of the paper is to highlight applications of SED approaches. In order to achieve this objective, papers with varied topics that related to SED are evaluated.
\end{abstract}

Keywords: Fatigue behaviour, Strain energy density, Fracture mechanics, Welded joints

\section{Introduction}

Fatigue, as widely known, is a phenomenon observed on mechanical components under cyclic loading. Due to the sudden and unexpected nature of fatigue based failures, determination of fatigue related parameters is crucial in any engineering design.

The importance of fatigue is no exception for welded joints, which are widely used in many engineering components and constructions. But it must be stated that the geometrical complexity of welds and heat related changes in welded material properties, make accurate determination of fatigue parameters a challenging task. Therefore, modern methods for evaluating the fatigue of welds are continuously developed and improved.

Local strain energy density (SED) approach is one of such modern methods, currently used in evaluation of fatigue. While the idea of using strain energy as a material parameter is not new, developments in computer aided analyses and calculations provided the method the necessary increase in mathematical accuracy and ease of use, increasing its use in fatigue estimations. Proposed by Lazzarin et al. [1],[2], SED approaches are derived from the calculation of strain energy in a designated control volume near notch tip to determine an energy parameter to estimate the initiation of fatigue failure.

\section{Öz}

Mekanik bileșenlerin yorulmaya karșı tasarımları ani ve beklenmedik yorulma hasarlarını önlemek için hayati önem tașır. Kaynaklı bağlantıların ısı sebebiyle değişen malzeme özellikleri ve kaynak dikișlerinin geometrisinden kaynaklanan karmașık doğası sebebiyle yorulmaya karșı tasarlanmaları çok daha zorlu bir görev haline gelmiștir. Ylllar içinde yorulma ile ilgili parametreleri hassas ve efektif șekilde belirleyebilecek yöntemler geliştirilmiștir. Bu makalede, birim șekil değiștirme enerji yoğunluğu yaklașımlarına ve onların yorulma incelemelerinde kullanımlarına dayanan calıșmaların güncel bir literatür incelemesi sunulmuştur. Teorik bir temelin verilmesi ile birlikte, bu makalenin ana odağı birim sekil değistirme enerji yoğunluğu yaklaşımlarının uygulamalarını vurgulamaktır. Bu amacı yerine getirmek için, birim şekil değiştirme enerji yoğunluğu ile ilgili çeşitli konulara sahip makaleler incelenmiștir.

Anahtar kelimeler: Yorulma davranıșı, Birim șekil değiștirme enerji yoğunluğu, Kırılma mekaniği, Kaynaklı birleștirmeler

\section{Theoretical basis and applications of SED approaches}

Elastic and plastic deformations occur during cyclic loading. This causes dissipation of heat and an increase in internal potential energy. The increase in this strain related potential energy continues until a state of equilibrium is reached or fatigue damage occurs. Thus, the amount of strain energy at which fatigue damage occurs can be considered a damage parameter.

By considering the strain energy per unit volume, a strain energy density parameter can be calculated (SED). SED can be determined as a damage parameter that encompasses the both phases of fatigue damage which are crack initiation and propagation. A generalized equation for calculating the total SED is presented Eq. 1 [1],[2];

$$
W_{o}=\int_{0}^{\varepsilon_{i j}} \sigma_{i j} d \varepsilon_{i j}
$$

Where $W_{o}$ is SED, $\sigma_{i j}$ is total stress components and $\varepsilon_{i j}$ is total strain components.

Originally developed for sharp $\mathrm{V}$ notches, the simplified equation serves as a basis for the local SED approaches. Methods, which will be discussed in this paper, modifying the original approach are further developed over time to cover different stress states, loading components and notches. 


\subsection{Sharp V notch SED approach}

According to Neuber's stress averaging method [3], when a sharp $\mathrm{V}$ notch is in question, instead of maximum stresses at the tip of the notch, a stress value averaged over a finite length is considered. Elaborating on this idea, Lazzarin and Zambardi [1],[2] proposed that SED values around the tip of a sharp V notch can be averaged over a finite volume with a radius of $R$. The finite volume in question is named critical volume and presented in Figure 1. The averaged SED value is considered to be material parameter for static or cyclic crack initiation.

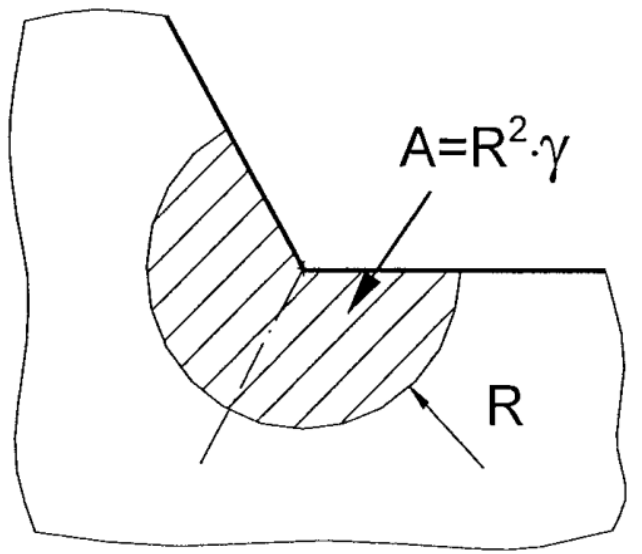

Figure 1: Critical volume surrounding the notch tip [1].

The area $A(R)$ of critical volume is represented in Eq. 2 as following;

$$
A(R)=R^{2} \cdot \gamma
$$

Where $\gamma$ is the internal notch angle based on the notch opening angle $2 \alpha=2 \pi-2 \gamma$. Both notch angles are schematically represented in Figure 2.

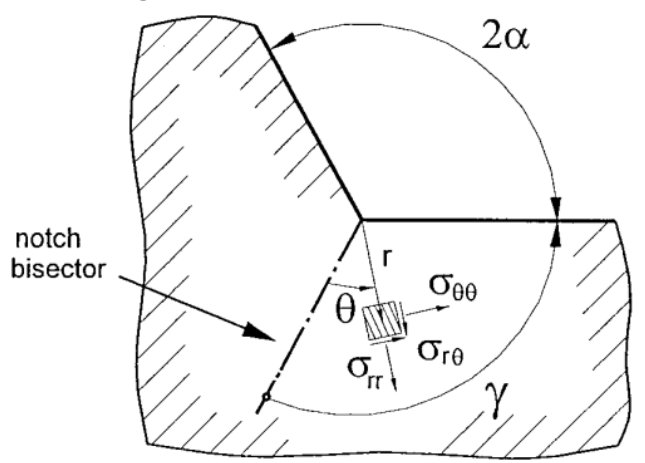

Figure 2: Notch angles on polar coordinate system for notch tip [1].

By averaging the strain energy over $A(R)$ area, Eq. 3 representing the average local SED $\bar{W}$ is acquired.

$$
\bar{W}=\frac{E_{s}(R)}{A(R)}=\frac{1}{E} e_{1}\left(K_{1}^{N}\right)^{2} R^{2\left(\lambda_{1}-1\right)}+\frac{1}{E} e_{2}\left(K_{2}^{N}\right)^{2} R^{2\left(\lambda_{2}-1\right)}
$$

Where $E_{s}$ is the strain energy, $e_{1}$ and $e_{2}$ are total strain energy coefficients, $K_{1}^{N}$ and $K_{2}^{N}$ are the Notch Stress Intensity Factors (NSIF), $\lambda_{1}$ and $\lambda_{2}$ are Williams' eigenvalues. Mode I and Mode II stress distributions are denominate with subscripts 1 and 2 respectively. Total strain energy coefficients $e_{1}$ and $e_{2}$ can be expressed as functions of notch opening angle. This relation is presented in Figure 3 and total strain energy coefficients is plotted against the notch opening angle $2 \alpha$.

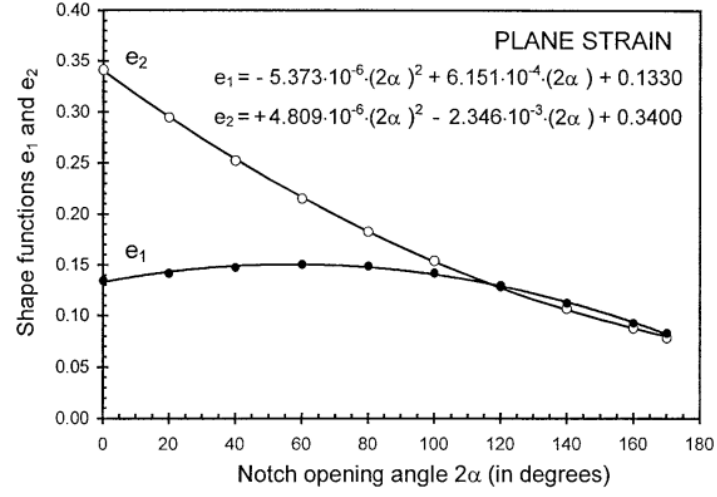

Figure 3: Plot of total strain energy coefficients $e_{1}$ and $e_{2}$ against the notch opening angle $2 \alpha$ [1].

As stated in [1], specimens under loads will fail when average local SED $\bar{W}$ in the control volume reaches a critical SED value $W_{c}$. In other words $\bar{W} \leq W_{c}$ relation exists between these SED values. $W_{c}$ can be determined according to Eq. 4 .

$$
W_{c}=\frac{\sigma_{U}^{2}}{2 E}
$$

Where $\sigma_{U}$ is the ultimate strength and $E$ is Young's modulus. As it can be observed from Eq. $4, W_{c}$ is a material parameter, independent from the loading type and the notch opening angle. Since the radius $R$ of area of the critical volume is also considered to be a material parameter, average local SED $\bar{W}$ can be considered independent from the geometry as well.

Based on these conclusions, $\bar{W}$ value is considered to be applicable to fatigue assessments. However, instead of the calculation of $\bar{W}$, average local SED range $\Delta \bar{W}$ is taken into consideration [4].

Results of analytical energy based approaches were compared to experimental data by various scientists over the years. In this article, more recent studies on the topic of the application of energy based approaches are evaluated.

Expanding on the previous findings, Lazzarin et al. [5], presented a discussion regarding the relation between SED and notch stress intensity factors using some welded joints and plates with sharp V-notches. Assessed fatigue data was previously evaluated in [6], in relation to the averaged SED and was expanded with the addition of more experimental results. Average SED plotted against number of cycles (W-N) are presented in Figure 4.

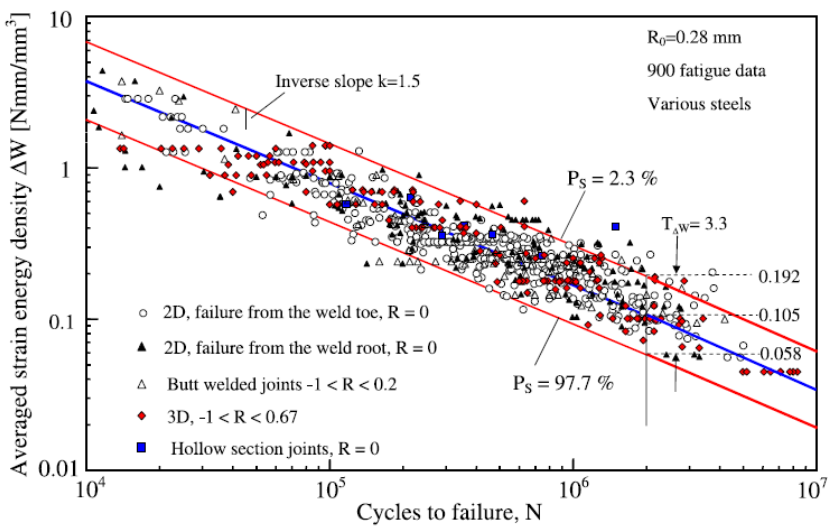

Figure 4: Fatigue strength of steel welds as a function of the averaged local SED [5]. 
Highly stressed regions of V-notches were evaluated via the use of the control volume which was used to average SED. By presenting a relation between SED and NSIF, determining the NSIF values were simplified. This approach was determined to be fit for purpose of fatigue strength evaluation of welded joints and calculation of theoretical stress concentration factors $K_{t}$ for blunt U-shaped and V-shaped notches and holes.

\subsection{Applications of SED approaches}

By considering a different approach, Payten et al. [7], proposed a model which takes the energy dissipated in the material on a macroscopic level as a parameter of the creep-fatigue damage occurred in the material, expanding the use of strain energy in fracture mechanics. The method considered both stress and temperature data in creep-fatigue assessments. Estimations made by the proposed energy density exhaustion method were compared with the creep-fatigue test results of low alloy ferritic steels and showed good agreement with the experimental creep-fatigue lives.

Park et al. [8], assessed the fatigue life behaviour of rolled AZ31 based on the low cycle fatigue tests performed along the rolling direction. In the study, instead of average SED, a total strain energy based model was used, incorporating plastic SED as a fatigue parameter to approximate the fatigue life of the specimens. While stress and strain based fatigue assessment approaches was difficult to use due to the characteristics of the material, the experimental results and the estimations made by the model based on total strain energy showed good correlation (Figure 5). The study was further expanded in [9] to evaluate the anisotropic fatigue behaviour of rolled Mg-3Al$1 \mathrm{Zn}$ alloy comparing the fatigue of normal direction and rolling direction to the rolling plane. An energy based approach which took the mean stress effect into consideration, was used to evaluate the anisotropic fatigue life behaviour of the specimens.
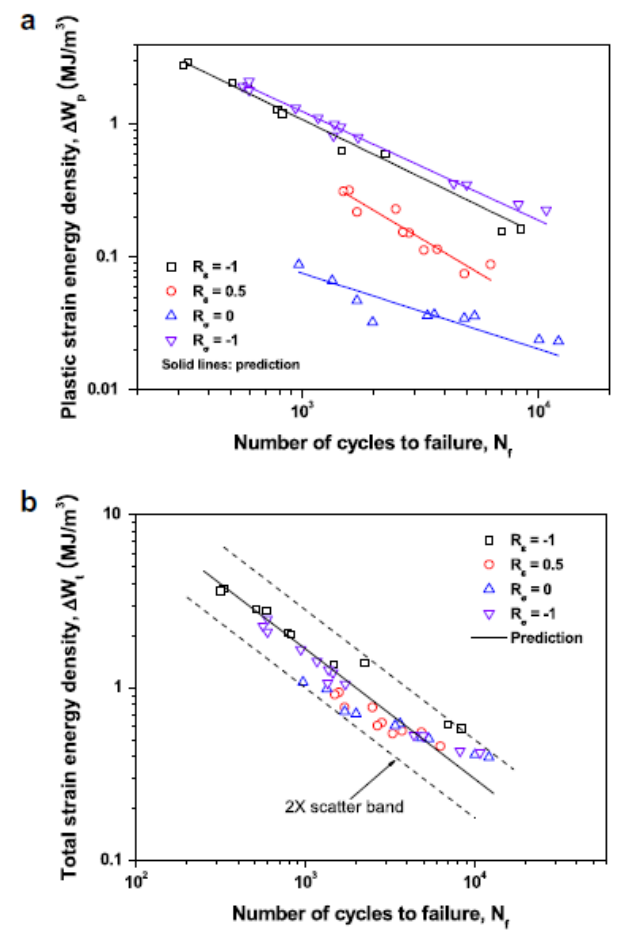

Figure 5: Fatigue life estimations based on. (a): Plastic SED, and (b): Total SED [8].
By considering the working conditions of gas turbine engines, a multi-axial fatigue assessment was considered in [10]. In order to determine fatigue life of specimens under shear or biaxial bending loads Scott-Emuakpor et al. presented a method based on strain energy. Energy based shear and multiaxial fatigue life estimation criteria were proposed. The methods were used to evaluate the fatigue test results from three different aluminium alloy specimens. Energy based methods successfully managed to estimate the fatigue life of specimens. Further improving on the subject, a new hysteresis loop representation was presented for SED, in [11], to improve the accuracy of fatigue life estimations performed using SED. Experiments were carried out on Al 6061-T6 specimens and SED per cycle was observed and a new representation of the hysteresis loop was developed based on the significant changes in the SED during failure cycles.

Further study based on these works was presented by Ozaltun et al. [12]. Based on hysteresis energy, a new fatigue life estimation framework was developed. The new framework was intended to perform fatigue life estimations for in service gas turbine materials, taking the aging effects caused by cyclic loadings into consideration to calculate the remaining life of the turbine. The method was validated by comparison between results of calculations using the model and fatigue test results of Al 6061-T6, showing good agreement between two results.

Kim et al. [13], investigated the pre-strain influence on the low cycle fatigue and high cycle fatigue behaviour of $\mathrm{Fe}-18 \mathrm{Mn}$ twinning-induced plasticity steel. A modified energy based approach was used to determine the effects of pre-strain and mean stress on the fatigue life and was further developed to successfully establish a correlation between low cycle and high cycle fatigue data. The method also proved to be successful in fatigue life estimations of cyclically non-stabilized materials.

In order to develop an efficient total fatigue life computation method, Maksimovic et al. incorporated cyclic deformation properties obtained from low cycle fatigue with a fatigue crack growth model based on SED concept [14]. Fatigue tests were conducted on flat specimens with central hole made of quenched and tempered high alloy high temperature steel 13H11N2V2MF. Estimations made using the computation model were in agreement with the experimental results as it can be observed in Figure 6.

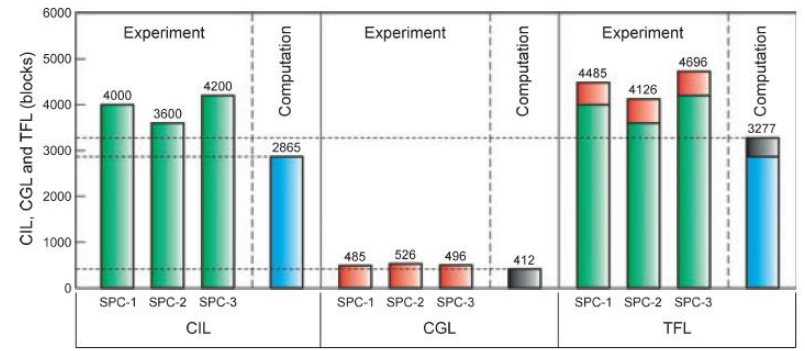

Figure 6: Comparison of experimental and computational results of crack initial life, crack growth life and total fatigue life [14].

Based on the approach developed by Lazzarin et al., Mehran et. al. assessed the applicability of averaged SED criteria to estimate the critical fracture load in notched plates of functionally graded materials [15]. Experimental results on functionally graded austenitic-martensitic steel specimens with blunt V-notches under mode I loading were evaluated using J integral and averaged SED criteria. Both criteria were 
applicable in estimating the critical fracture load in specimens. While the averaged SED was established as a criterion for fatigue estimation for homogenous materials, this study proved that the approach can also be applied to nonhomogenous materials.

In order to present an accurate low cycle fatigue life estimation for gas turbine components, using Bayes' theorem a probabilistic method with an energy-based damage parameter was developed by Zhu et. al. [16]. The framework was devised to include the uncertainty of various fatigue damage parameters as required and is presented in Figure 7. Included damage parameters were Smith-Watson-Topper (SWT), plastic strain energy density (PSED), Fatemi-Socie criterion (FSC), thermodynamic entropy (TE), viscosity-based damage parameter (VDP) and generalized damage parameter (GDP).

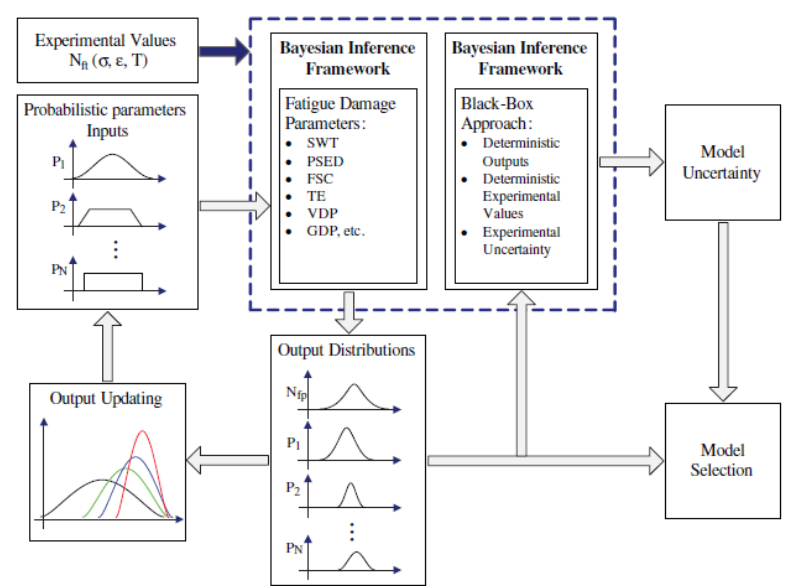

Figure 7: Probabilistic low cycle fatigue life estimation framework using Bayes' theorem [16].

In the study, the model uncertainty for the generalized damage parameter, Smith-Watson-Topper and plastic SED were quantified by measuring the differences between model estimations and experimental data. Experimental data were acquired from specimens made of GH4133 tested at various temperatures. In [17], the research further expanded with a new model to also consider the fatigue-creep damage. A plastic SED based fatigue-creep damage parameter $\Delta W_{p} \sigma_{\max }^{1+n^{\prime}}$ was developed. The proposed model estimated the fatigue behaviour of GH4133 compared to plastic SED approach and Smith-Watson-Topper with relative success, determining that plastic SED approach is inadequate to account for the creepfatigue damage on its own.

Walat et al. presented a criteria based on strain and energy to determine the low cycle fatigue life under multiaxial stress state [18]. The criterion in question can be represented as Eq. 5 in its most basic form. However, reading the original publication is highly recommended to understand the use and the development of the criteria.

$$
W_{\eta s}(t)=\max
$$

Where $W_{\eta s}$ is the tangent component of the energy parameter on the critical plane. Since the energy criteria previously used in high cycle range and performed accurately in low cycle range, as shown in this study, it can be said that the proposed criteria is universal and can be applied to both high and low cycle fatigue.
While mainly an experimental study, Shariati et al. [19], presented interesting results by performing stress controlled uniaxial fatigue tests on Polyoxymethylene (POM). Based on the experimental results, the strain range, strain ratcheting, SED and the slope of the stress-strain hysteresis loops were determined. The stress, strain and energy approaches were used to calibrate material constants. The stress and energy approaches were determined to be relatively better for the fatigue life estimations of POM compared to strain approaches. In [20], Lazzarin et al. investigated the fracture behaviour of isostatic graphite specimens with inclined key-hole notches using the previous developments in SED as basis. A local energy criterion was used for the fracture evaluation, enabling presentation of all experimental data in a unified scatter band regardless of the notch geometry and mode mixity. Mode mixity was evaluated based on Eq. 6. The proposed criterion accurately estimated the critical loads of the specimens.

$$
\chi=\frac{2}{\pi} \arctan \left[\frac{K_{2}^{N}}{K_{1}^{N}}\right]
$$

In order to more accurately study the behaviour of cyclic fractures, Boulenouar et al. [21], developed a numerical crack propagation model under mixed mode loading conditions. In order to calculate the stress intensity factors under mode I and mixed mode loading, a finite element code was modified with displacement extrapolation method. The SED approach was mainly used to improve the code to estimate the new course of crack propagation.

In [22] criterion based on the averaged SED proposed by Lazzarin et al. was compared with Leguillon's and Carpinteri's critera from the Finite Fracture Mechanics theory. Data acquired from the experimental studies in literature was used to compare each criterion and a good agreement was found in all cases. SED and Carpinteri approaches generally showed conservative results compared to approach based on Legillon's criterion. In addition to this study, Lazzarin et al. provided closed form relationships for the J-integral and the averaged SED for U-shaped and blunt V-shaped notches under torsion in [23]. The expressions were applied to experimental data. The data consisted of torsion tests performed on cracked, notched and plain specimens at $-60{ }^{\circ} \mathrm{C}$. The analytical expressions was validated by a number of finite element analyses and shown agreement with the results.

Based on the local average SED approach and NSIF, Ferro [24], provided numerical simulation analyses of the residual stress distribution near V-notch tip caused by cyclic loading. A model based on the local strain energy was proposed to determine the fatigue resistance of pre-stressed components. The method required calculation of the asymptotic residual stress field in term of NSIF accurately.

In order to extend the use of SED for fatigue estimations at elevated temperatures, Berto et al. investigated the stress controlled fatigue tests results of $\mathrm{Cu}-\mathrm{Be}$ alloy specimens at temperatures up to $650{ }^{\circ} \mathrm{C}$ in [25]. Two different specimen geometries were used for the uniaxial tension experiments which were hourglass shaped and plates with a central hole. SED approach was successfully used to compile all fatigue data in a single scatter band regardless of the geometry of specimens.

Further expanding the wide range of applications of SED approaches, Torabi et al. presented experimental, theoretical 
and numerical study on brittle fracture of notched Polymethylmethacrylate (PMMA) specimens, in [26]. Fracture tests under mode II loading were performed on Brazilian disk (Figure 8) type specimens which have V-notches with end holes. Fracture loads were estimated using averaged SED criterion and showed good correlation with the experimental results.

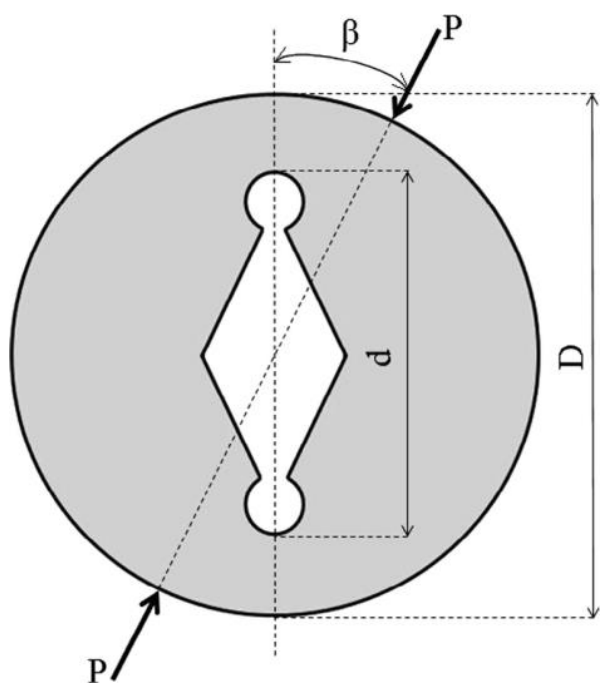

Figure 8: Brazilian disk specimen which has V-notches with end holes [26].

By considering fatigue test results of C45 carbon steel, Inconel 718 and directionally solidified superalloy DZ125 specimens tested at temperatures of $250{ }^{\circ} \mathrm{C}, 500{ }^{\circ} \mathrm{C}$, and $850{ }^{\circ} \mathrm{C}$ respectively, Gallo et al. [27], evaluated the accuracy of average SED approach when evaluating the fatigue data of notched components at elevated temperatures. Average SED approach was able to compile the fatigue data to a single narrow scatter band regardless of the component geometry.

Wang et al. proposed a modified SED exhaustion model in order to estimate creep-fatigue life under tension hold only [28]. The model took mean stress and stress relaxation into consideration as well. Experiments performed on specimens made of Grade 91 steel, Alloy 617 and 304 stainless steel were evaluated using the proposed model. According to these estimations, most of the test results were in an acceptable range within a scatter band. The proposed model resulted in more accurate estimations compared to previously used methods for creep-fatigue life calculations.

Chandran et al. proposed a new, more direct approach based on the net section strain energy amplitude to determine the growth rates of fatigue cracks [29]. The approach used the change in net section strain energy amplitude with crack extension unlike methods based on range of stress intensity factor. The proposed approach relatively simplified the calculation of crack growth rate of miniature specimens of Ti$6 \mathrm{Al}-4 \mathrm{~V}$ alloy.

In [30], Zhu et al. proposed a new model for estimation of fatigue life of metals based on mean stress corrected strain energy. The dissipated strain energy was modified by adding two mean stress correction factors and mean stress corrected total SED was derived as presented in Eq. 7.

$$
\Delta W_{t}^{m}=\left(\frac{\sigma_{\max }}{\sigma_{f}^{\prime}}\right)^{2} \Delta W_{e}\left(\frac{\sigma_{\max }}{\sigma_{f}^{\prime}}\right)^{\left(1+n^{\prime}\right) / n^{\prime}} \Delta W_{p}=C\left(N_{f}\right)^{\alpha}
$$

where $\sigma_{f}^{\prime}$ is fatigue strength coefficient, $C$ is fatigue ductility exponent, $\alpha$ is material constant. 13 different experimental datasets were evaluated using the proposed model and comparisons with generalized damage parameter, Morrow, Smith-Watson-Topper and Walker were made. Proposed model managed to achieve more accurate estimations.

Further improving SED approaches, Razavi et al. performed extensive brittle fracture tests on pre-cracked granite samples subjected to various in-plane loading mixities in [31]. Also theoretical estimations of fracture loads were made using an approach based on average SED criterion. Experimental data were in good correlation with the theoretical estimations.

In addition to the articles summarized in this paper, [32]-[35] should be considered for further reading for more information on frequently used terms in aforementioned articles, low cycle and high cycle fatigue, mean stress effects and damage parameters.

\section{Conclusions}

As presented by the many articles presented in this study, SED based approaches show promising results in estimating fatigue and fracture related parameters of notched and welded specimens with different loading types and wide variety of different materials. Also, it is possible to use SED approaches in estimations at various temperatures, both high and low. The independency of the approach from the geometry of the specimens is also worth mentioning considering the possibility of complex geometries of welded constructs.

Future research in this field to incorporate SED based approaches in fatigue and fracture related estimations can be fruitful in determining the full capabilities of energy based methods. By determining energy based material parameters for different materials, fatigue related calculations can be performed with less effort. Thus, fatigue studies based on strain energy should be encouraged to contribute to establishing a standard for fatigue related energy parameters.

\section{References}

[1] Lazzarin P, Zambardi R. "A finite-volume-energy based approach to predict the static and fatigue behavior of components with sharp V-shaped notches". International journal of fracture, 112(3), 275-298, 2001.

[2] Lazzarin P, Zambardi R. "The equivalent strain energy density approach re-formulated and applied to sharp V-shaped notches under localized and generalized plasticity". Fatigue \& Fracture of Engineering Materials \& Structures, 25(10), 917-928, 2002.

[3] Neuber H. Theory of Notch Stresses. Berlin, Germany, Splinger-Verlag, 1958.

[4] Lazzarin P, Sonsino CM, Zambardi R. "A notch stress intensity approach to assess the multiaxial fatigue strength of welded tube-to-flange joints subjected to combined loadings". Fatigue \& Fracture of Engineering Materials \& Structures, 27(2), 127-140, 2004.

[5] Lazzarin P, Berto F, Zappalorto M. "Rapid calculations of notch stress intensity factors based on averaged strain energy density from coarse meshes: Theoretical bases and applications". International Journal of Fatigue, 32(10), 1559-1567, 2010. 
[6] Lazzarin P, Berto F, Gomez FJ, Zappalorto M. "Some advantages derived from the use of the strain energy density over a control volume in fatigue strength assessments of welded joints". International Journal of Fatigue, 30(8), 1345-1357, 2008.

[7] Payten WM, Dean DW, Snowden KU. "A strain energy density method for the prediction of creep-fatigue damage in high temperature components". Materials Science and Engineering: A, 527(7-8), 1920-1925, 2010.

[8] Park SH, Hong SG, Lee BH, Bang W, Lee CS. "Low-cycle fatigue characteristics of rolled $\mathrm{Mg}-3 \mathrm{Al}-1 \mathrm{Zn}$ alloy". International Journal of Fatigue, 32(11), 1835-1842, 2010.

[9] Hong SG, Park SH, Huh YH, Lee CS. "Anisotropic fatigue behavior of rolled Mg-3Al-1Zn alloy". Journal of Materials Research, 25(5), 966-971, 2010.

[10] Scott-Emuakpor O, George T, Cross C, Shen MHH. "Multi-axial fatigue-life prediction via a strain-energy method". AIAA Journal, 48(1), 63-72, 2010.

[11] Scott-Emuakpor O, George T, Cross C, Shen MH. "Hysteresis-loop representation for strain energy calculation and fatigue assessment". The Journal of Strain Analysis for Engineering Design, 45(4), 275-282, 2010.

[12] Ozaltun H, Shen MH, George T, Cross C. "An energy based fatigue life prediction framework for in-service structural components". Experimental Mechanics, 51(5), 707-718, 2011.

[13] Kim YW, Kim G, Hong SG, Lee CS. “Energy-based approach to predict the fatigue life behavior of pre-strained Fe-18Mn TWIP steel". Materials Science and Engineering: A, 528(13-14), 4696-4702, 2011.

[14] Maksimovic S, Posavljak S, Maksimovic K, Nikolic V, Djurkovic V. "Total fatigue life estimation of notched structural components using low-cycle fatigue properties". Strain, 47(2), 341-349, 2011.

[15] Mehran S, Rouhi S, Ramzani B, Barati E. "Fracture analysis of functionally graded materials with U-and V-notches under mode I loading using the averaged strain-energy density criterion". Fatigue \& Fracture of Engineering Materials \& Structures, 35(7), 614-627, 2012.

[16] Zhu SP, Huang HZ, Ontiveros V, He LP, Modarres M. "Probabilistic low cycle fatigue life prediction using an energy-based damage parameter and accounting for model uncertainty". International Journal of Damage Mechanics, 21(8), 1128-1153, 2012.

[17] Zhu SP, Huang HZ, He LP, Liu Y, Wang Z. "A generalized energy-based fatigue-creep damage parameter for life prediction of turbine disk alloys". Engineering Fracture Mechanics, 90, 89-100, 2012.

[18] Walat K, Kurek M, Ogonowski P, Łagoda T. "The multiaxial random fatigue criteria based on strain and energy damage parameters on the critical plane for the low-cycle range". International Journal of Fatigue, 37, 100-111, 2012.

[19] Shariati M, Hatami H, Yarahmadi H, Eipakchi, HR. "An experimental study on the ratcheting and fatigue behavior of polyacetal under uniaxial cyclic loading". Materials \& Design, 34, 302-312, 2012.

[20] Lazzarin P, Berto F, Ayatollahi MR. "Brittle failure of inclined key-hole notches in isostatic graphite under in-plane mixed mode loading". Fatigue \& Fracture of Engineering Materials \& Structures, 36(9), 942-955, 2013.
[21] Boulenouar A, Benseddiq N, Mazari M. "Strain energy density prediction of crack propagation for 2D linear elastic materials". Theoretical and Applied Fracture Mechanics, 67, 29-37, 2013.

[22] Lazzarin P, Campagnolo A, Berto F. "A comparison among some recent energy-and stress-based criteria for the fracture assessment of sharp V-notched components under Mode I loading". Theoretical and Applied Fracture Mechanics, 71, 21-30, 2014.

[23] Lazzarin P, Zappalorto M, Berto F. "Averaged strain energy density and J-integral for U-and blunt V-shaped notches under torsion". International Journal of Fracture, 188(2), 173-186, 2014.

[24] Ferro P. "The local strain energy density approach applied to pre-stressed components subjected to cyclic load". Fatigue \& Fracture of Engineering Materials \& Structures, 37(11), 1268-1280, 2014.

[25] Berto F, Gallo P, Lazzarin P. "High temperature fatigue tests of a $\mathrm{Cu}-\mathrm{Be}$ alloy and synthesis in terms of linear elastic strain energy density". Key Engineering Materials, 627, 77-80, 2015.

[26] Torabi AR, Campagnolo A, Berto F. "Local strain energy density to predict mode II brittle fracture in Brazilian disk specimens weakened by V-notches with end holes". Materials \& Design, 69, 22-29, 2015.

[27] Gallo P, Berto F. "Advanced materials for applications at high temperature: fatigue assessment by means of local strain energy density". Advanced Engineering Materials, 18(12), 2010-2017, 2016.

[28] Wang RZ, Zhang XC, Tu ST, Zhu SP, Zhang CC. “A modified strain energy density exhaustion model for creep-fatigue life prediction". International Journal of Fatigue, 90, 12-22, 2016.

[29] Chandran KR, Cao F, Newman JC. "Fatigue crack growth in miniature specimens: The equivalence of $\Delta \mathrm{K}$-correlation and that based on the change in net-section strain energy density". Scripta Materialia, 122, 18-21, 2016.

[30] Zhu SP, Lei Q, Huang HZ, Yang YJ, Peng W. "Mean stress effect correction in strain energy-based fatigue life prediction of metals". International Journal of Damage Mechanics, 26(8), 1219-1241, 2017.

[31] Razavi SMJ, Aliha MRM, Berto F. "Application of an average strain energy density criterion to obtain the mixed mode fracture load of granite rock tested with the cracked asymmetric four-point bend specimens". Theoretical and Applied Fracture Mechanics, 97, 419-425, 2018.

[32] Radaj D, Sonsino CM, Fricke W. Fatigue Assessment of Welded Joints by Local Approaches. Cambridge, England, Woodhead Publishing, 2006.

[33] Karakas Ö. "Consideration of mean-stress effects on fatigue life of welded magnesium joints by the application of the Smith-Watson-Topper and reference radius concepts". International Journal of Fatigue, 49, 1-17, 2013.

[34] Karakaş Ö. “Application of neuber's effective stress method for the evaluation of the fatigue behaviour of magnesium welds". International Journal of Fatigue, 101, 115-126, 2017.

[35] Karakaş Ö, Zhang G, Sonsino CM. "Critical distance approach for the fatigue strength assessment of magnesium welded joints in contrast to Neuber's effective stress method". International Journal of Fatigue, 112, 21-35, 2018. 